\title{
HOW TO DECIDE WHICH OBLIQUE IMAGE HAS THE HIGHEST MAPPING POTENTIAL FOR MONOPLOTTING METHOD: A CASE STUDIES ON RIVER EROSION AND FLOODS
}

\author{
Mihaela Triglav-Čekada ${ }^{a}$, Vasja Bric ${ }^{\text {a }}$, Matija Zorn ${ }^{b}$
}

\author{
${ }^{\text {a }}$ Geodetic institute of Slovenia, Jamova cesta 2, SI-1000 Ljubljana, Slovenia - mihaela.triglav@ gis.si \\ ${ }^{\mathrm{b}}$ Anton Melik Geographical Institute, Scientific Research Centre of the Slovenian Academy of Sciences and Arts, Gosposka ulica \\ 13, SI-1000 Ljubljana, Slovenia
}

\author{
Commission V, WG V/5
}

KEY WORDS: Monoplotting, interactive orientation of images, oblique images, digital elevation models, lidar

\begin{abstract}
:
When studying the development of different geomorphic processes, floods, glaciers or even cultural heritage through time, one cannot rely only on regular photogrammetrical procedures and metrical images. In a majority of cases the only available images are the archive images with unknown parameters of interior orientation showing the object of interest in oblique view. With the help of modern high resolution digital elevation models derived from aerial or terrestrial laser scanning (lidar) or from photogrammetric stereo-images by automatic image-matching techniques even single nonmetric high or low oblique image from the past can be applied in the monoplotting procedure to enable 3D-data extraction of changes through time. The first step of the monoplotting procedure is the orientation of an image in the space by the help of digital elevation model (DEM). When using oblique images tie points between an image and DEM are usually too sparse to enable automatic exterior orientation, still the manual interactive orientation using common features can resolve such shortages. The manual interactive orientation can be very time consuming. Therefore, before the start of the manual interactive orientation one should be certain if one can expect useful results from the chosen image. But how to decide which image has the highest mapping potential before we introduce a certain oblique image in orientation procedure? The test examples presented in this paper enable guidance for the use of monoplotting method for different geoscience applications. The most important factors are the resolution of digital elevation model (the best are the lidar derived ones), the presence of appropriate common features and the incidence angle of the oblique images (low oblique images or almost vertical aerial images are better). First the very oblique example of riverbank erosion on Dragonja river, Slovenija, is presented. Than the test example of September 2010 floods on Ljubljana moor is discussed. Finally, case study from November 2012 floods is presented. During November 2012 floods an initiative was launched to gather as much non-metrical images of floods as possible from casual observers (volunteered image gathering). From all gathered images the guidelines presented before helped to pick out $21 \%$ images which were used for monoplotting.
\end{abstract}

\section{INTRODUCTION}

The lidar digital elevation models (DEM), due to their accuracy and resolution, did revolutionized possibilities for application of an old photogrammetric method mainly called monoplotting (Radwan and Makarovič, 1980; Luhmann et al., 2006). Monoplotting is a photogrammetric method, which enables $3 \mathrm{D}$ data acquisition from just one image with the help of DEM of any kind (terrain or surface models). With the DEM and known interior orientation parameters of camera used, the exterior orientation parameters of image in the coordinate system of DEM can be derived. When exterior orientation parameters are searched manually this method is called interactive orientation (Rönnholm et al., 2003; Triglav Čekada et al., 2011). Basically we are looking for the best agreement between the content of the image and back-projection of the DEM onto that image content (Figure 1). In the cases, when suitable or enough tie points (common features) is hard to find for automatic exterior orientation, manual interactive orientation enables good alternative. DEM with smaller grid sizes enables better results of exterior orientation, as more detail can be seen on the back-projection of the DEM.

Monoplotting can be applied to oblique or vertical aerial imagery (Höhle, 2008; dos Santos et al. 2010), satellite imagery (Willneff et al., 2010) or terrestrial imagery (Rönnholm et al., 2003; Triglav-Čekada et al., 2011; Triglav-Čekada and Radovan, 2013; Bozzini et al., 2012; Wiesmann et al., 2012). Monoplotting method is applied also in integrated system called Pictometry; where different professional aerial cameras, with some having oblique view, are integrated in one imaging system. It enables direct georeferencing and acquisition of data mainly for 3D city modelling (Höhle, 2008).

Monoplotting has a big mapping potential for the data acquisition from the archive imagery of cultural and natural heritage, for the natural disaster monitoring or studying the development of different geomorphic processes through time. Oblique imagery monoplotting was already successfully applied for the study of the long-time vegetation changes (Bozzini et al. 2012), long-time glacier changes (Triglav-Čekada et al., 2011; Triglav-Čekada et al., 2014; Wiesmann et al. 2012), 
multitemporal landslide monitoring (Travelletti et al., 2012) and flood monitoring (Triglav-Čekada and Radovan, 2013).

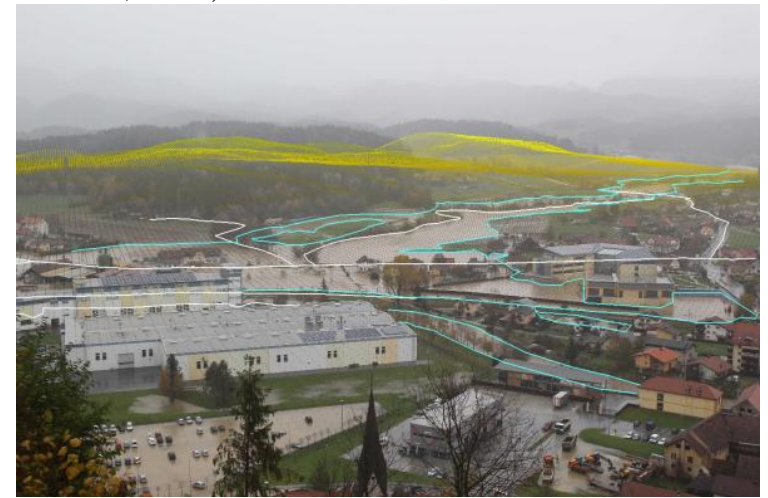

Figure 1. Superimposition of $5 \mathrm{~m} \times 5 \mathrm{~m}$ digital terrain model (grey to yellow dots), roads (white lines) and the derived flood boundaries (blue lines) on the image of floods in Šoštanj, Slovenia, on November 52012 (underlying photo: Dean Tonkli).

When dealing with natural disaster monitoring by means of volunteered imagery gathering (from casual observers), like the November 2012 floods monitoring in Slovenia (Triglav-Čekada and Radovan, 2013), one can be stuffed with different terrestrial and even aerial oblique images (photographs and video clips) of different qualities, acquired by different unknown cameras, having different distortions. To decide as quickly as possible, which images have the biggest mapping potential, some simple measure is needed to assess the mapping potential of monoplotting method. The most important factors, which influence on this are: the coverage of content in question presented on the image, incidence angle of the oblique image resulting in changeable scale and the grid size of the used DEM.

Therefore the purpose of this paper is to give simple guidelines for deciding which oblique image has the biggest mapping potential by monoplotting method. Through case studies presented in this paper the proposals are given how to overcome the shortages of different oblique images.

\section{METHOD}

The manual interactive orientation of an image using detailed DEM gives as a result the exterior orientation parameters of the image (three rotations, the location of the camera's perspective centre and the scale factor in the centre of the image), was already described in detail in Triglav-Čekada et al. (2011). When the image is oriented correctly, the superimposed DEM points fit to the detail of the image very well. The method is the most suitable for areas with easily recognisable distinctive topographical features (e.g. hills, mountain peaks). When applying this method to lowlands, the interactive orientation based just on DEM is not possible. As the same procedure of interactive orientation can also be applied using vector break lines (Karjalainen et al., 2006) it was decided to amend our point based interactive orientation with vector data. Still DEM represents the basis for calculation of backprojection, vector data is attached to DEM points. With including roads, rivers and creeks as break lines in interactive orientation also the lowlands can be correctly manually oriented by this method (Figure 5, $6)$.

For successful exterior orientation of an image, also interior orientation parameters of the image need to be known. The interior parameters could be computed with self-calibration (Luhmann et al., 2006). But it is not trivial to compute interior orientation parameters of archive images due to the lack of control points. Additionally, when dealing with archive images, we sometimes can use images, which are not complete. Old books and magazines can be a valuable source of archive images, but some published images were cropped due for better visual effect (better composition of image content). This unknown extent of image cropping presents a problem when trying to do selfcalibration. In the case of long-time and multitemporal studies, e.g. glacier studies, such cropped images might be the only source to examine the past stages of the glacier (Triglav Čekada et al., 2014). Therefore, we included in the procedure of interactive orientation also a search for distortion parameters. The procedure of interactive orientation was divided in two steps. First the best-fit of exterior orientation parameters is searched for (three rotations, the location of the camera's perspective centre and the scale factor). Afterwards the distortion parameters are introduced (radial and decentring distortion) again manually. In both steps the parameters are manually changed, searching for the best fit of DEM back-projection to the image content. Original image is not resampled.

\section{THE MONOPLOTTING MAPPING POTENCIAL OF AN SINGLE OBLIQUE IMAGE}

The mapping potential of the oblique image depends on the image content, the varying scale of the image and possibility to accurately enough orient the image in the space.

Image content should represent enough details relevant for the study of geomorphological changes through time. Those details should be represented in good resolution and clearly visible. The resolution in which a detail is presented depends on the image scale. But it should not be neglected that oblique images have very varying scale. Therefore the pixel area on the ground is of different size and form from one to the other side of the image. On Figure 2 this principle is presented through back-projection of digital terrain model (DTM) points. 

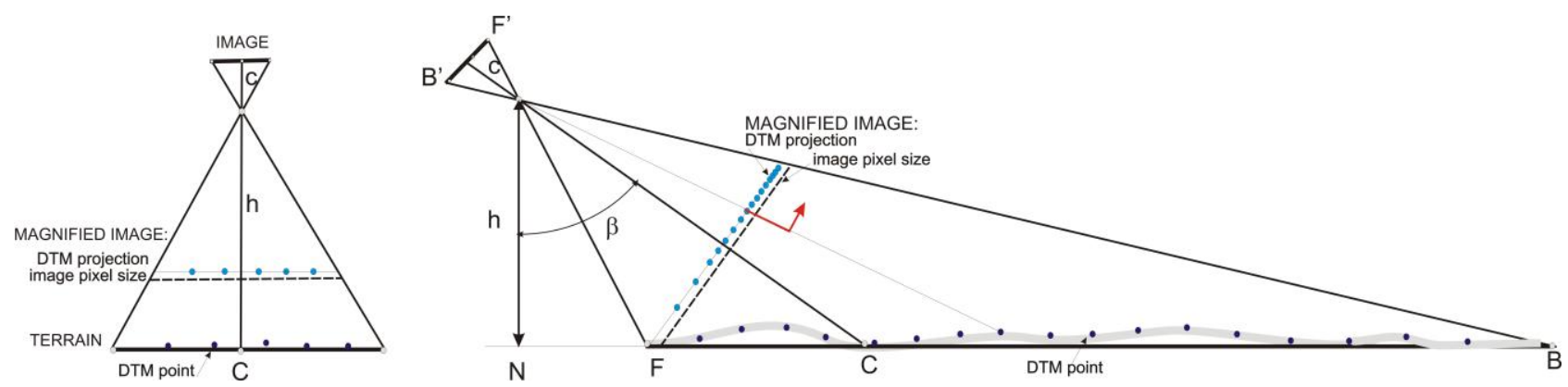

Figure 2. The DTM superimposition on image content for aerial (left) and oblique image (right).

The varying scale of the image influences also on the accuracy of the image orientation with the help of the DEM. Common features used to connect the content of the image and DEM superimposition should be easily recognisable in both and should be evenly distributed through the whole image. When using high oblique images, the poor scale of some image parts also disables the identification of good common features in such parts, therefore worse accuracy of orientation can be expected.

After we have oriented the image correctly in the space, the superimposed DEM points will fit very well to the image content, at least in parts of the image with the larger scale. Now the process of mapping of our object of interest can start. The resolution of DEM again plays a very important role, as we cannot measure details, which are smaller than the grid of the DEM. Prior to the acquisition of data from oblique image it should be decided, which part of the image still has good enough image resolution and which is hindered by the poor scale and should therefore not be used for the acquisition. The mapping should stop where the superimposed DEM grid length becomes smaller that the pixel size of the image; marked with red arrow on Figure 2.

A simple measure to decide if DTM or lidar data used has good enough resolution for monoplotting is the cartographic scale $(M)$ in which the mapping results should be presented. The drawing accuracy $(D A)$ on a map was defined through the cartographic history as a minimal line thickness, which can be drawn by a pen to a sheet of paper representing a map. In general the drawing accuracy is better than $0.25 \mathrm{~mm}$, with smallest value of $0.13 \mathrm{~mm}$. For general calculations usually drawing accuracy of $0.2 \mathrm{~mm}$ is used (Maling, 1989). The drawing accuracy $0.2 \mathrm{~mm}$ gives by the Equation 1 for a mapping scale of 1:1000 a geometrical accuracy of $0.2 \mathrm{~m}$ - the size of this error in nature:

$$
G A=D A \cdot M
$$

The drawing accuracy $D A[\mathrm{~m}]$ and the desired map scale $M$ can be connected with grid size of DTM $d$ [m] by the Equation 2 (Maling, 1989) and with the average lidar point density $\rho$ [points $/ \mathrm{m}^{2}$ ], when not dealing with heavily vegetated areas, by Equation 3 (Triglav-Čekada et al., 2010):

$$
\begin{aligned}
& d=\frac{M \cdot D A \cdot 10^{-3}}{2} \\
& \rho=\frac{1}{\left(M \cdot D A \cdot 10^{-3} / 2\right)^{2}}
\end{aligned}
$$

By Equations 2 and 3 the cartographic scale of 1:5000 needs lidar point density of $4 \mathrm{pt} / \mathrm{m}^{2}$ or DTM with $0.5 \mathrm{~m}$ $\times 0.5 \mathrm{~m}$ grid size (Table 1$)$.

\begin{tabular}{|l|l|l|l|}
\hline Map scale & GA & $\mathrm{d}$ & $\rho$ \\
\hline $1: 1000$ & $0.2 \mathrm{~m}$ & $0.1 \mathrm{~m} \times 0.1 \mathrm{~m}$ & $100 \mathrm{pt} / \mathrm{m}^{2}$ \\
\hline $1: 5000$ & $1 \mathrm{~m}$ & $0.5 \mathrm{~m} \times 0.5 \mathrm{~m}$ & $4 \mathrm{pt} / \mathrm{m}^{2}$ \\
\hline $1: 10.000$ & $2 \mathrm{~m}$ & $1 \mathrm{~m} \times 1 \mathrm{~m}$ & $1 \mathrm{pt} / \mathrm{m}^{2}$ \\
\hline $1: 50.000$ & $5 \mathrm{~m}$ & $5 \mathrm{~m} \times 5 \mathrm{~m}$ & $0.04 \mathrm{pt} / \mathrm{m}^{2}$ \\
\hline
\end{tabular}

Table 1: Map scale, GA - geometrical accuracy, $\mathrm{d}$ - grid size of DTM, $\rho$ - lidar point density.

\section{DATA AND RESULTS}

\subsection{The riverbank erosion of the Dragonja river}

Two non-metrical oblique images were used for measuring riverbank erosion of Dragonja river, Slovenia, induced by the floods of September 2010. One image was taken before the floods in 2010 and one after the floods in the year 2012 (Figure 3 and 4). The cameras with which the images were taken are not known, meaning we do not have interior orientation parameters of these images. The standpoint of the images was known only approximately and was not the same for both images.

The lidar data used for monoplotting were acquired in winter of 2011 at the start of the National aerial lasers scanning project of Slovenia. Average overall density of all laser returns at this area was 5 points $/ \mathrm{m}^{2}$ and the digital terrain model (DTM) with $1 \mathrm{~m}$ $\times 1 \mathrm{~m}$ grid size was derived from it also. For the orientation of both images unclassified lidar point cloud and DTM were used.

Due to the highly oblique images, the manual interactive absolute orientation resulted in poor accuracy. As common features (tie patches) only four trees in the back side of the images were used (marked on the Figure 3 and 4 with arrows) as well as the flat riverbed in the forehand of the image. Due to the poor reflectance of lidar points from water the interpolated 
DTM at this area helped a great deal. No lines were seen on the images, therefore for the orientation only superimposed lidar points were used. The hills in the back of the image are too far to help in the orientation.

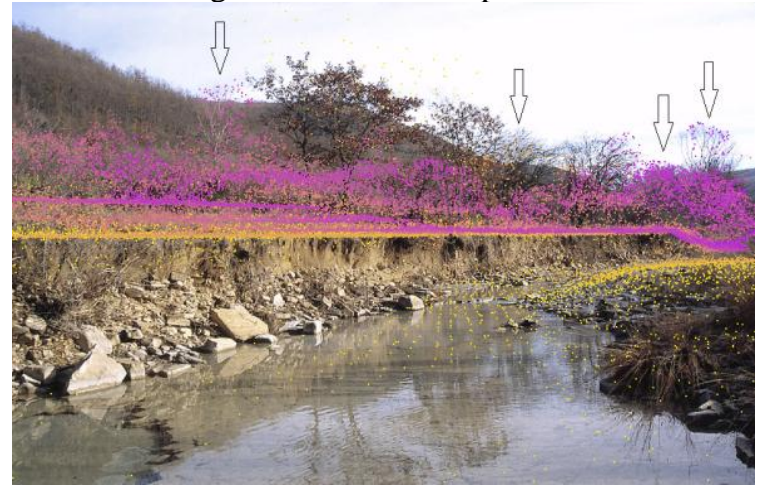

Figure 3. The riverbank of the Dragonja river before 2010. In yellow are lidar points near the standpoint and in purple those almost $110 \mathrm{~m}$ away. The points more than $110 \mathrm{~m}$ away from the standpoint are deleted. Only $40 \%$ of the original points is presented (underlying photo: M. Zorn).

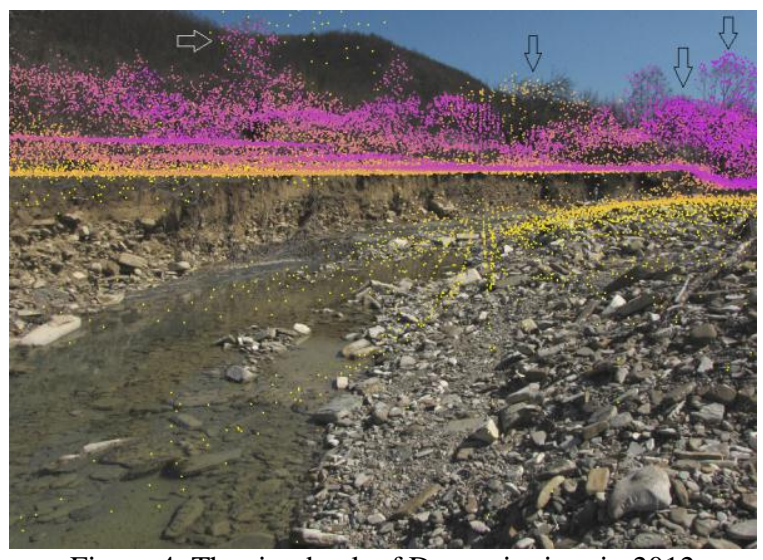

Figure 4. The riverbank of Dragonja river in 2012 (underlying photo: M. Zorn).

The riverbed side erosion can be seen in a form of group of trees in the middle of the image (Figure 3), which were eroded away together with riverbank, as they are not seen anymore on the Figure 4. Therefore at least 1-2 m planimetric movement of riverbank edge can be expected.

Due to sparse and very poor distribution of tie patches, the distortion corrections of the image were not searched for in the process of interactive orientation. If we check the fitting of upper riverbank line on Figure 3 in the at most left position the superimposed lidar points lie $35 \mathrm{~cm}$ above the upper riverbank line seen on the image, at the at most right position they are $18 \mathrm{~cm}$ above the riverbank line, respectively. This implies that this image has nonnegligible distortions. As we did not take them into the account the precision of exterior orientation is poor.

We were still able to measure the $2 \mathrm{~m} \pm 2 \mathrm{~m}$ planimetric shift of riverbank between both images. The big error of the measurement implies that this result is not very reliable.
From the Equation 3 or Table 1 it can be seen that the lidar data used in this example should enable $1 \mathrm{~m}$ graphical accuracy. But the searched changes were just a little bigger than expected graphical accuracy and due to the poor exterior orientation it can be concluded that results are not reliable.

\subsection{September 2010 floods in Ljubljana moor}

Due to high precitipation between 16 and 19 September 2010 floods affected Ljubljana moor (Komac and Zorn, 2013). The water spilled on almost flat terrain and stayed there for a couple of days. For a location near Podpeč we obtained two oblique image sets presenting the flood in two dates: first were taken by hand from a hill above Podpeč (Figure 5) on 20 September, and the second set was taken by hand from a helicopter flying above the Podpeč on 23 September 2010 (Figure 6). The images were taken by the same non-metrical camera Canon PowerShot SX IS. These image sets enable a study of water recession in time span of three days. In this paper just one image pair is presented.

For the monoplotting a photogrammetrical DTM $5 \mathrm{~m} \times 5 \mathrm{~m}$ and lidar derived DTM $1 \mathrm{~m} \times 1 \mathrm{~m}$ (based on lidar density $10 \mathrm{pt} / \mathrm{m}^{2}$ ) were used. In the interactive absolute orientation first the DTM $5 \mathrm{~m} \times 5 \mathrm{~m}$ and road and river vectors were applied. After this, the lidar DTM was used to introduce small corrections in the orientation results. For the mapping just a little more than a lower half of image content was used in both cases, due to the poor image scale on the other parts of the image (see the white lines on Figure 6). For the flood boundary extraction at first lidar DTM was used. The lines were generalized, taking approximately one point out of DTM on a length of 5-10 m. To speed up the monoplotting the DTM $5 \mathrm{~m} \times 5 \mathrm{~m}$ was used in further acquisitions.

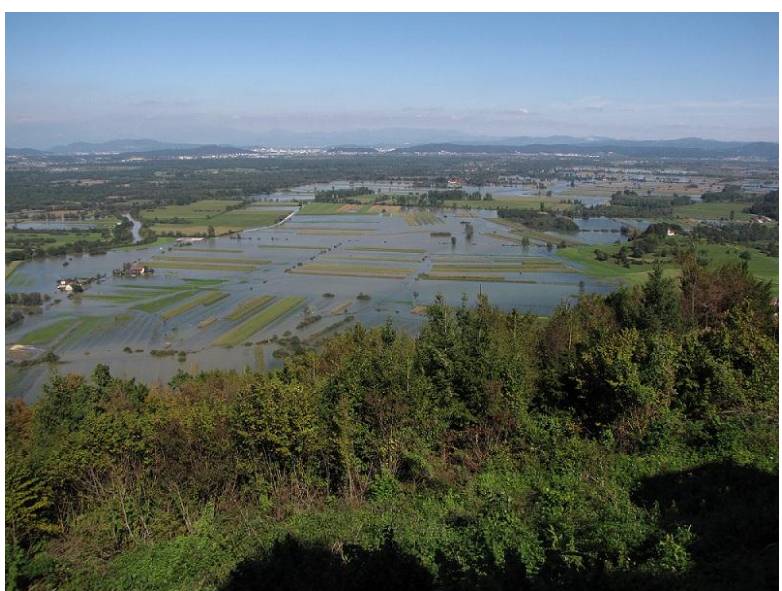

Figure 5. Flood on Ljubljana moor flood taken by hand from a hill above Podpeč on 20 September 2010 with non-metrical camera (photo: M. Zorn). 


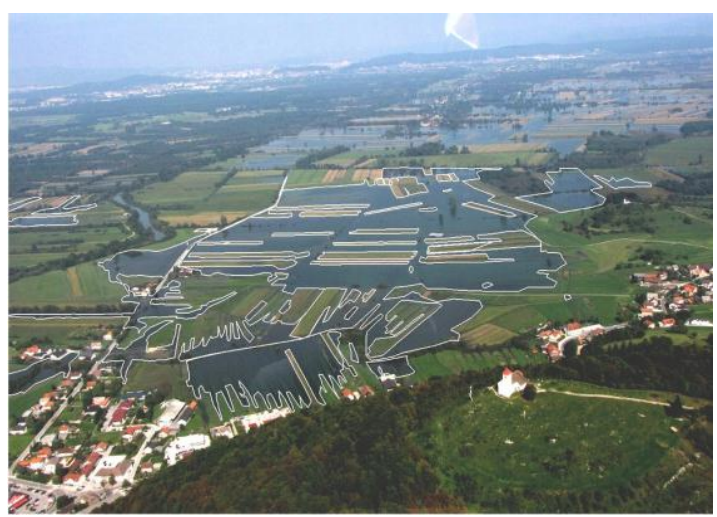

Figure 6. Flood on Ljubljana moor taken by hand from a helicopter on 23 September 2010 with non-metrical camera (photo: M. Zorn). The flood boundaries acquired from this image are given as white lines.

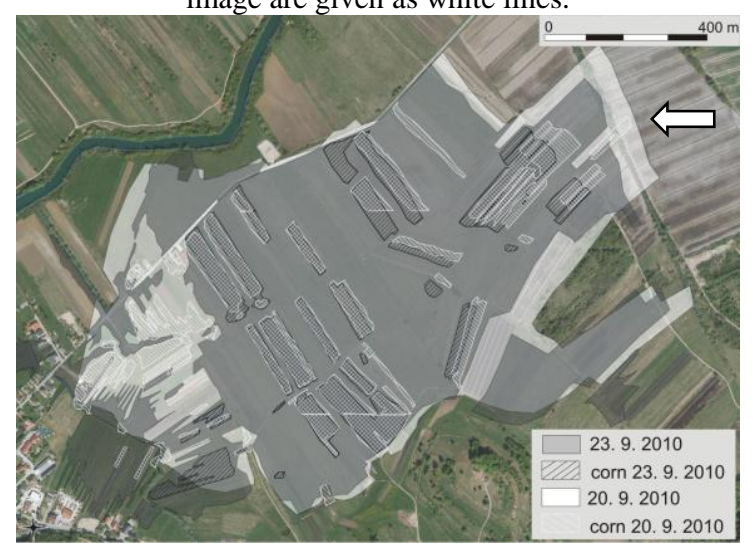

Figure 7. A part of Ljubljana moor flood in September 2010.

On the Figure 7 the extracted flooded areas are presented on the ortophoto. The white area presents the flood area on the 20 September. As first image is more oblique than the second image, the erroneously placed flood boundary at the upper right corner of Figure 7 is seen (see the arrow). This boundary should be located app. $40 \mathrm{~m}$ more to the left to coincide with the flood boundary of 23 September shown in grey. The main source for this error of location is the changing scale factor of oblique image, which influences on the accuracy of image absolute orientation. The used lidar DTM should enable monoplotting with geometrical accuracy of $2 \mathrm{~m}$ (mapping scale 1:10.000). When using DTM $5 \mathrm{~m} \times 5 \mathrm{~m}$ the geometrical accuracy should still be $10 \mathrm{~m}$, which is smaller than the $40 \mathrm{~m}$ observed.

The used oblique images still enabled the calculation of flood area recession from 10 ha to 7 ha.

\subsection{November 2012 floods}

Encouraged by the results of flood boundary extraction from oblique non-metrical images in 2010, the same technique was applied for 5 and 6 November 2012 floods. An initiative was launched to gather volunteered images of floods by casual observers. These floods affected almost the whole upper half of the Slovenia, being the most severe on $400 \mathrm{~km}$ of river segments (Triglav-Čekada and Radovan, 2013). For the monoplotting method the photogrammetrical DTM $5 \mathrm{~m}$ $\times 5 \mathrm{~m}$ which covers the whole Slovenia was available. From the public we received altogether 102 oblique images and one video taken from higher standpoints (e.g. from a hilltop) and also from the air. These images were taken by different cameras having different resolutions and distortions. To speed up the process of monoplotting and to produce results as soon as possible we had to decide which images have the highest mapping potential for monoplotting process. The next criteria ware used:

- image content should cover as broad area as possible - to map as big areas as possible from a single image (see Figure 9 versus Figure 8)

- the best are aerial images or those taken from high hills - low oblique images

- the content of the image should show at least three or more easily recognisable parts of roads to speed up the interactive absolute orientation by the vector break lines

- just small image distortions should be visible on used images

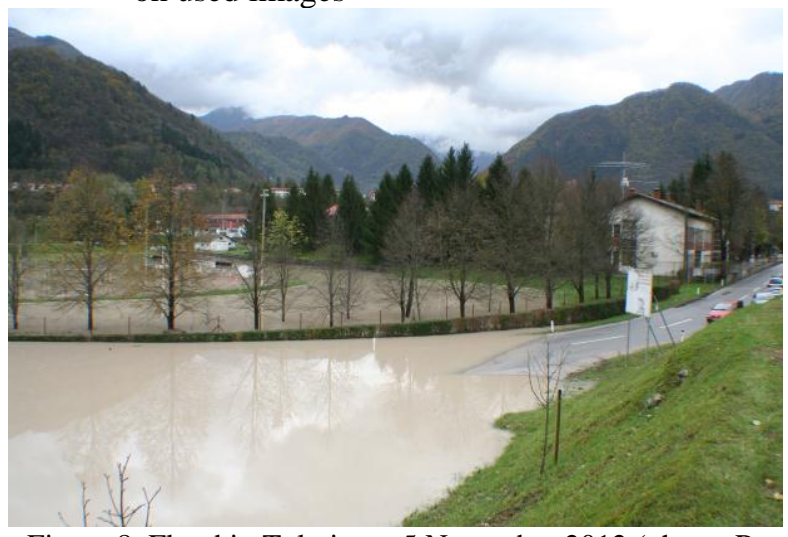

Figure 8. Flood in Tolmin on 5 November 2012 (photo: R. Lipušček).

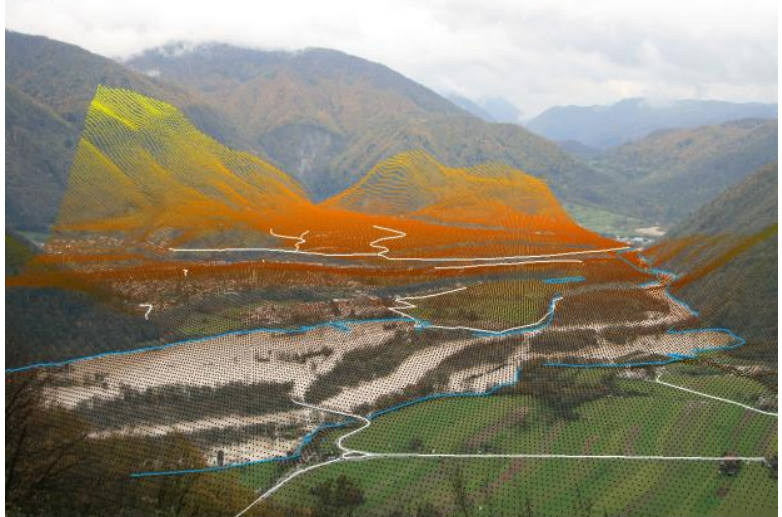

Figure 9. Flood in Tolmin on 5 November 2012 (underlying photo: B. Močnik)

Some $45 \%$ of received images were classified as potentially useful fulfilling the upper criteria. For the actual flood mapping 22 images and 12 sequences from one video were used (e.g. Figure 1). On average around 4 hours was needed for manual interactive orientation and acquisition of flood border per image. 
With the monoplotting method we successfully mapped $48 \mathrm{~km}$ of the most affected river sections or 1439.4 ha of flooded areas (Figure 10).

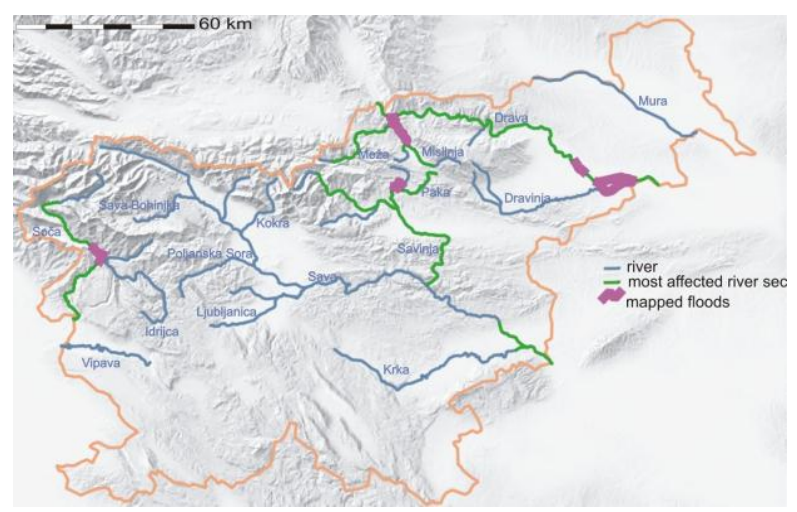

Figure 10. The most affected river sections (green lines) of the November 2012 floods in Slovenia and the mapped flooded areas from volunteered oblique images (pink).

\section{CONCLUSION}

As the examples 4.1 and 4.2 have shown, the most important factor, which define what it is possible to acquire from a single image by the monoplotting procedure is the DTM or lidar point cloud resolution. It defines the appropriate map scale in which the results can be presented. For example if having almost vertical image and the lidar point cloud with density 5 points $/ \mathrm{m}^{2}$, it enables mapping in scale 1:5000 (the geometrical accuracy of $1 \mathrm{~m}$ ).

The high-resolution DTM or lidar point cloud also enable easier tie points definition between the content of the image and the DTM back-projection. Good distinguishable tie points have also to be uniformly distributed on the image, to enable good results of interactive absolute orientation. The vector break lines (e.g. streets, river borders) may help a lot with the orientation.

If an image has non-negligible distortions, the removal of distortion should also be included in the process. The image may be resampled to distortion free image prior to the interactive orientation, or additional parameters may be added in the process of interactive orientation, which influence on the DTM backprojection.

When having highly oblique image the influence of varying scale on the accuracy of interactive orientation and the possibility to extract details from the image should not be neglected. The image content in front of the line where pixel size becomes the same or smaller as back-projected DTM grid size length should be used for orientation and acquisition purposes.

These guidelines may help to carry out bigger project, e.g. processing of a great number of volunteered images of different natural disasters (e.g. presented floods of November 2012 in Slovenia in section 4.3) or studying the geomorphic changes through time.

\section{ACKNOWLEDGEMENTS}

This work was partly financially supported by the Slovenian Research Agency projects No. Z6-4182, L64048 and $\mathrm{J} 2-5479$.

\section{REFERENCES}

Bozzini, C., Conedera, M., Krebs, P., 2012. A new monoplotting tool to extract georeferenced vector data and ortorectified raster data from oblique non-metric photographs, International Journal of Heritage in the Digital Era, 1(3), pp. 499-518.

dos Santos, D.R., Dal Poz, A.P., Dalmolin, Q., 2010. Indirect orientation of images using control points extracted by the means of monoplotting model, The Photogrammetric Journal of Finland, 22(1), pp. 60-76.

Höhle, J., 2008. Photogrammetric measurements in oblique aerial images. Photogrametry Fernerkundung Geoinformation, 7-14.

Karjalainen, M., Hyyppä, J., Kuittinen, R., 2006. Determination of exterior orientation using linear features from vector maps, The Photogrammetric Record, 21(116), pp. 329-341.

Komac, B., Zorn, M., 2013. Extreme floods in Slovenia in September 2010. In: Geomorphological Impact of Extreme Weather, Dordrecht: Springer, pp. 121-139.

Luhmann, T., Robson, S., Kyle, S., Harley, I., 2006. Close Range Photogrammetry: Principles, techniques and applications. Dunbeath: Whittles Publishinig, 510 p.

Maling, D.H. 1989. Measurements from maps: principles and methods of cartometry. Oxford: Pergamon press. 577 p.

Radwan, M., Makarovič, B., 1980. Digital mono plotting system: improvements and tests, XIV Congress of the International society for photogrammetry, Hamburg, pp. 510-533.

Rönnholm, P., Hyyppä, H., Pöntinen, P., Haggrén, H., Hyyppä, J. 2003. A method for interactive orientation of digital images using backprojection of 3D data. The Photogrammetric Journal of Finland, 18(2), pp. 16-31.

Travelletti, J., Delacourt, C., Allemand, P., Malet, J.-P., Schmittbuhl, J. Taussaint, R., Bastard, M., 2012. Correlation of multitemporal ground-based optical images for landslide monitoring: Application, potential and limitations, ISPRS Journal of Photogrammetry and Remote Sensing, 70, pp. 39-55.

Triglav-Čekada, M., Crosilla, F., Kosmatin-Fras, M., 2010. Theoretical lidar point density for topographic mapping in the largest scales, Geodetski vestnik, 54(3), pp. 403-416.

Triglav-Čekada, M., Radovan, D., Gabrovec, M., Kosmatin Fras, M., 2011. Acquisition of the 3D boundary of the Triglav glacier from archived non-metric panoramic images. The Photogrammetrical Record, 26(133), pp. 111-129.

Triglav-Čekada, M., Radovan, D., 2013. Using volunteered geographical information to map the November 2012 floods in Slovenia, Natural Hazards Earth System Sciences, 13, pp. 2753-2762.

Triglav-Čekada, M., Zorn, M., Colucci, R.R., 2014. Area changes on Canin (Italy) and Triglav glaciers (Slovenia) from 1893 on based on archive imagery and lidar, Geodetski vestnik, 58(2), in press.

Wiesmann, S., Steiner, L., Pozzi, M., Bozzini, C., Bauder, A., Hurni, L., 2012. Reconstructing historic glacier states based on terrestrial oblique photographs, Proceedings - AutoCarto 2012 - Columbus, Ohio, USA, September 16-18.

Willneff, J., Poon, J., Fraser, C., 2010. Monoplotting applied to high-resolution satellite imagery, Journal of Spatial Science, 50(2), pp. 1-11. 